\title{
Note
}

J. Jpn. Soc. Colour Mater. (SHIKIZAI), 66 (6), 339-343 (1993)

\section{Preparation of Carbon-Metal Composite Particles}

\author{
H. Sugii*, D. Tateishi*, K. Esumi*, and H. Honda*
}

\begin{abstract}
Carbon-metal composite particles were prepared by "water-in-oil emulsion method" using ammonia water solutions containing both amphiphilic carbonaceous material and a metal salt such as $\left[\mathrm{Pt}\left(\mathrm{NH}_{3}\right)_{4}\right]$ $(\mathrm{OH})_{2}, \mathrm{Cu}(\mathrm{OH})_{2}$, or $\mathrm{AgNO}_{3}$. The results of the $\mathrm{X}$-ray diffraction and electron microscopy indicated that the morphology of spherical carbon-metal composite particles obtained by heattreatment was considerably dependent on the kind of metal salt.
\end{abstract}

Key-words : amphiphilic carbonaceous material, spherical carbon beads, carbon-metal composite

\section{Introduction}

Recently, it has been reported ${ }^{1,2)}$ that raw cokes oxidized with mixtures of sulfuric acid and nitric acid are soluble in alkaline aqueous solutions. These materials are called "amphiphilic carbonaceous material". Interestingly, an alkaline aqueous solution of amphiphilic carbonaceous material becomes viscous and finally loses fluidity to form a "carbonaceous gel". ${ }^{3)}$ Since amphiphilic carbonaceous material and many metal salts are easily soluble in alkaline water, it is possible to prepare carbon-metal composite particles from their aqueous mixtures. A few studies have previously been reported on the preparation of carbonmetal composites using polymer-metal complexes and carbonaceous materials containing metal compounds, but the control of the composite shape has not been attained. ${ }^{4-7)}$ Our new method for the preparation of spherical particles of carbon-metal composite is as follows. Mixed aqueous alkaline solutions of amphiphilic carbonaceous material and metal salts are added to an oil, resulting in the formation of a water-in-oil emulsion. The water is then removed from the water-in-oil emulsion. Finally, the spherical particles separated from the

Received Mar. 8, 1993

* Department of Applied Chemistry, Institute of Colloid and Interface Science, Science University of Tokyo, Kagurazaka, Shinjukuku, Tokyo 162 solution are heat-treated to obtain spherical particles of carbon-metal composite. Previously carbon-platinum spherical particles have been prepared by this technique. ${ }^{8)}$

This paper reports on the preparation of carbonmetal composite spherical particles, such as carbon -platinum, carbon-copper, and carbon-silver.

\section{Experimental}

The preparation of amphiphilic carbonaceous material using raw coke has been described in the previous report. ${ }^{3)}$ Three grams of the amphiphilic carbonaceous material and various amounts of metal salts were added to $100 \mathrm{ml}$ of ammonia water with pH 12 and shaken for $1 \mathrm{hr}$ at $25^{\circ} \mathrm{C}$. Then, 30 $\mathrm{m} l$ of the solution was poured into $500 \mathrm{~m} l$ of olive oil and stirred at $1200 \mathrm{rpm}$ at $90^{\circ} \mathrm{C}$ for $1 \mathrm{hr}$ to eliminate water. The samples obtained were washed with benzene and acetone, and then dried in vacuo. The heat-treatment of the samples was performed in the range of 200 to $1000^{\circ} \mathrm{C}$ for $1 \mathrm{hr}$ under nitrogen atmosphere. Metal salts used in this study were $[\mathrm{Pt}$ $\left.\left(\mathrm{NH}_{3}\right)_{4}\right](\mathrm{OH})_{2}, \mathrm{Cu}(\mathrm{OH})_{2}$, and $\mathrm{AgNO}_{3}$. Electron micrographs of the samples were taken by both a scanning electron microscope and a transmission electron microscope. Crystal structures of the samples were determined with an X-ray diffractometer. Elemental analysis of the samples was performed using EPMA. 


\section{Results and Discussion}

Before preparing carbon-metal composite particles, it is very important to check the solubility of metal salts and amphiphilic carbonaceous material in ammonia water solution at $\mathrm{pH} 12$. When various concentrations of $\left[\mathrm{Pt}\left(\mathrm{NH}_{3}\right)_{4}\right](\mathrm{OH})_{2}$ and $3 \mathrm{~g}$ of the amphiphilic carbonaceous material were added to $100 \mathrm{~m} l$ of ammonia water, the solutions were homogeneous up to $10 \mathrm{wt} \%$ of $\left[\mathrm{Pt}\left(\mathrm{NH}_{3}\right)\right](\mathrm{OH})_{2}$, and insoluble matter was observed at 15 and 20 wt\%. Similarly, the solutions containing $\mathrm{Cu}(\mathrm{OH})_{2}$ and $\mathrm{AgNO}_{3}$ were homogeneous up to 7.0 and 15.0 $\mathrm{wt} \%$ of the respective salts. Thus, a compatibility between the amphiphilic carbonaceous material and respective metal salts depends on the concentration of the metal salts. Since the amphiphilic carbonaceous material having acidic functional groups $^{1,2)}$ shows an anionic character due to the dissociation of the acidic functional groups in alkaline aqueous solutions, electrostatic attraction force between the cationic metal ions and the anionic carbonaceous material would be generated. This electric neutralization will result in the formation of

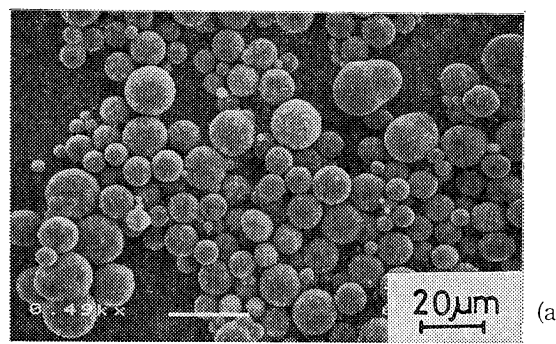

(a)

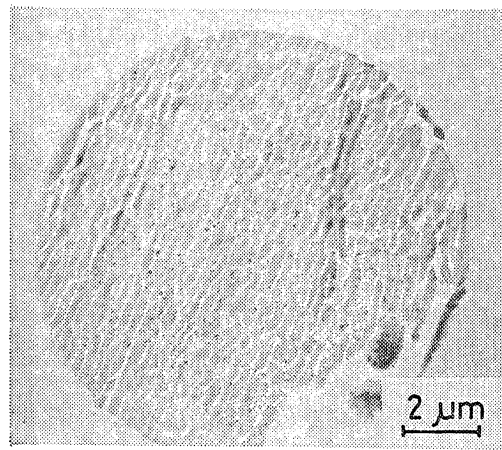

(b) insoluble matter. Therefore, in this work the preparation of carbon-metal composite particles was carried out using homogeneous solutions containing the amphiphilic carbonaceous material and a metal salt.

When the aqueous solution of ammonia water dissolving the amphiphilic carbonaceous material and $\left[\mathrm{Pt}\left(\mathrm{NH}_{3}\right)_{4}\right](\mathrm{OH})_{2}$ was poured into olive oil and stirred, a water-in-oil emulsion was formed. At $90^{\circ} \mathrm{C}$, the removal of water from the water-in-oil emulsion provided spherical carbon particles containing $\left[\mathrm{Pt}\left(\mathrm{NH}_{3}\right)_{4}\right](\mathrm{OH})_{2}$. A typical photograph of the spherical particles is given in Figure 1(a):

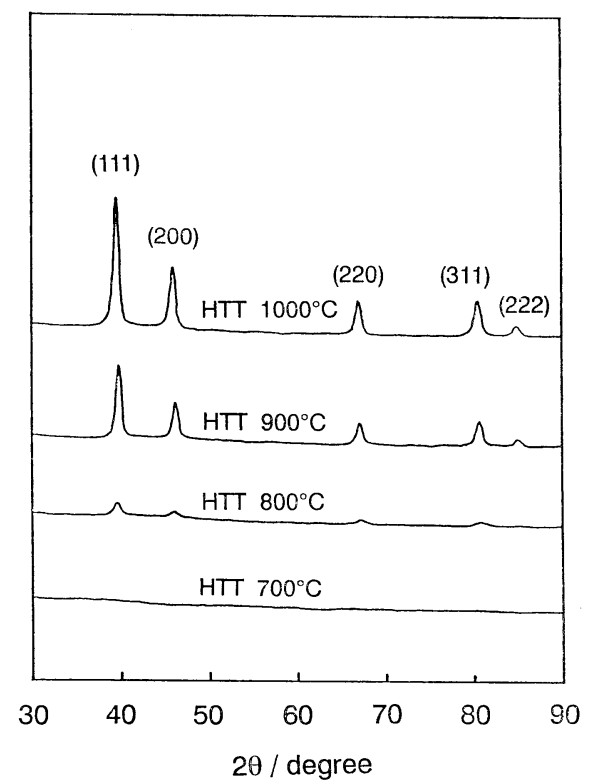

Fig. 2 Change in X-ray diffraction pattern of spherical carbon particles containing $10 \mathrm{wt} \%$ of $\left[\mathrm{Pt}\left(\mathrm{NH}_{3}\right)_{4}\right]$ $(\mathrm{OH})_{2}$ with HTT.

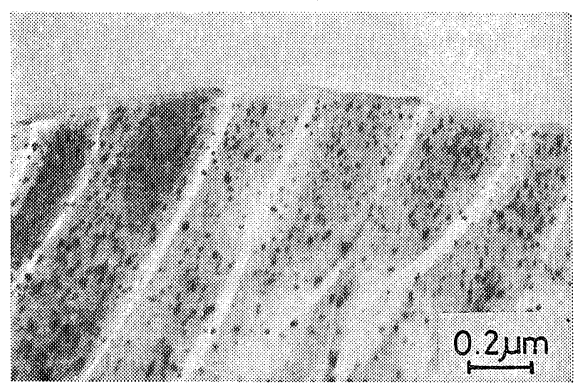

Fig. 1 (a) Electron micrograph of spherical carbon particles containing $10 \mathrm{wt} \%$ of $\left[\mathrm{Pt}\left(\mathrm{NH}_{3}\right)_{4}\right]$ $(\mathrm{OH})_{2} ;$ (b) sectional view of the sample heat-treated at $1000^{\circ} \mathrm{C}$. 


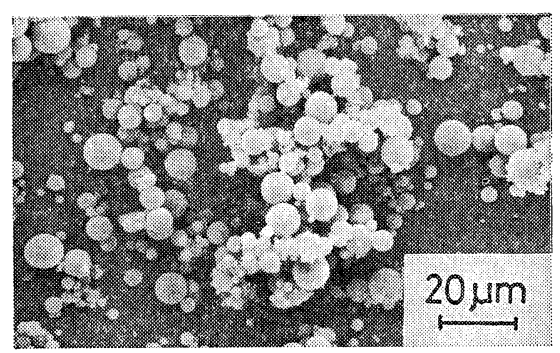

(a)

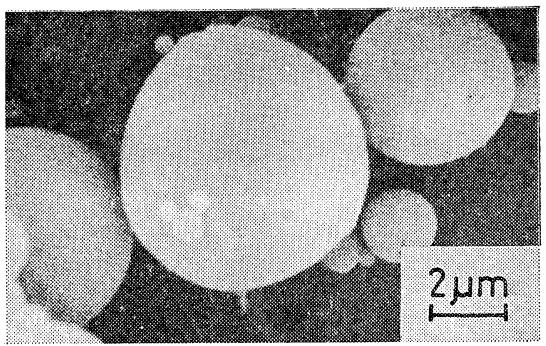

a $\mathrm{S}$

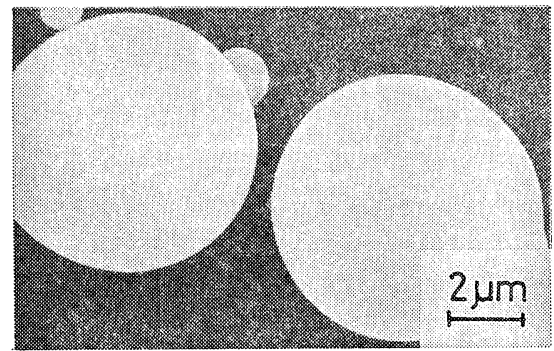

$p r e p$

H T T 500 C

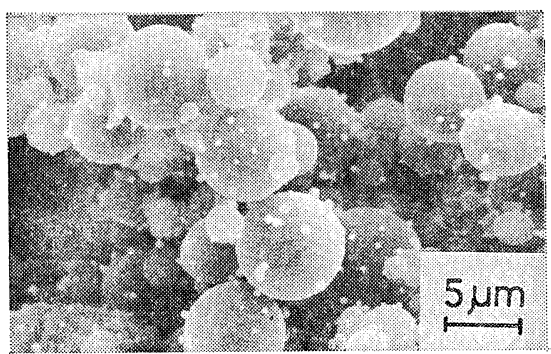

H T T

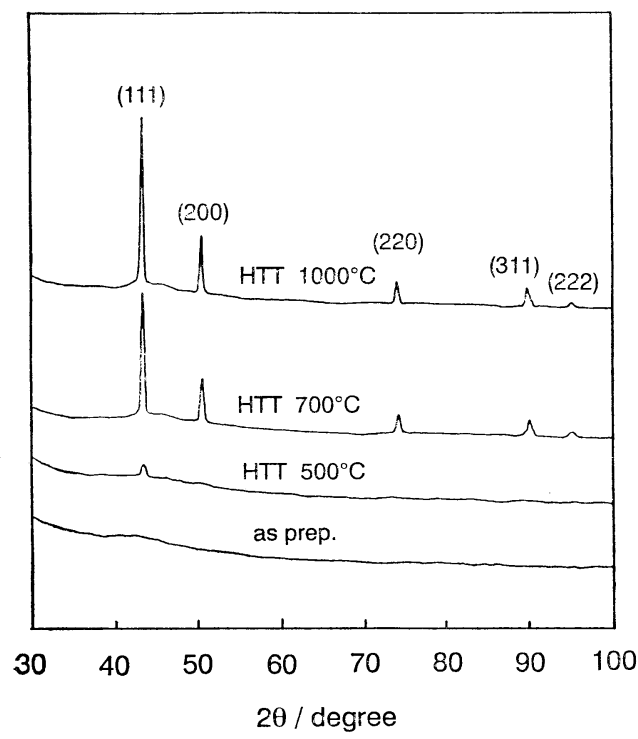

(b)
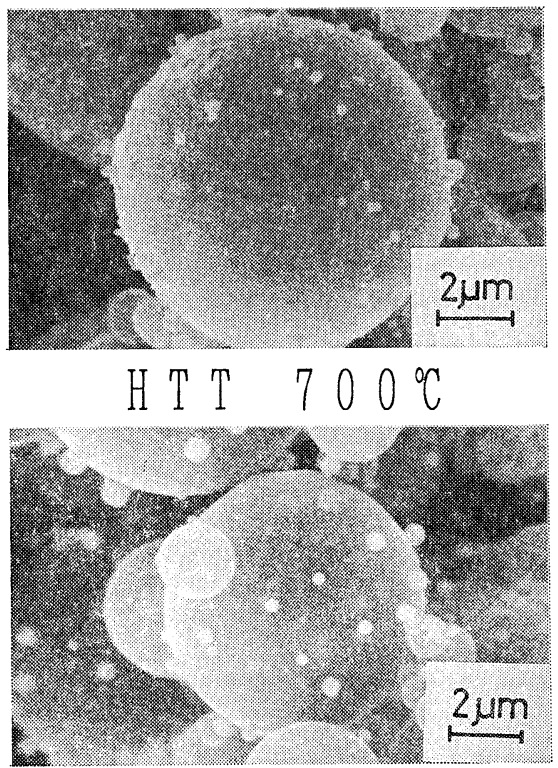

$1000 \%$

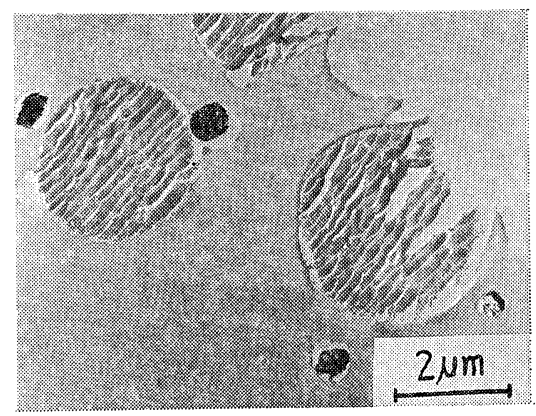

Fig. 4 (a) Electron micrographs of the samples in Fig.3 ;

(b) sectional view of the sample (containing $10 \mathrm{wt} \%$ of $\left.\mathrm{Cu}(\mathrm{OH})_{2}\right)$ heat-treated at $1000^{\circ} \mathrm{C}$

$\hookleftarrow$ Fig. 3 Change in X-ray diffraction pattern of spherical carbon particles containing $10 \mathrm{wt} \%$ of $\mathrm{Cu}(\mathrm{OH})_{2}$ with HTT. 
the average particle size ranges between 10 and 20 $\mu \mathrm{m}$. Further, the particles obtained with $10 \mathrm{wt} \%$ $\left[\mathrm{Pt}\left(\mathrm{NH}_{3}\right)_{4}\right](\mathrm{OH})_{2}$ were heat-treated. The X-ray diffraction measurement of the heat-treated particles (Figure 2) shows that no diffraction peaks are observed until heat-treatment temperature (HTT) of $700^{\circ} \mathrm{C}$. Above $800^{\circ} \mathrm{C}$ of $\mathrm{HTT}$ several new peaks, which are assigned to platinum metal, appear and their intensities increase with HTT, which indicates that $\left[\mathrm{Pt}\left(\mathrm{NH}_{3}\right)_{4}\right](\mathrm{OH})_{2}$ decomposes into platinum metal in the carbon matrix. Figure $1(\mathrm{~b})$ shows a sectional view of the carbon particles heat-treated at $1000^{\circ} \mathrm{C}\left(10 \mathrm{wt} \%\left[\mathrm{Pt}\left(\mathrm{NH}_{3}\right)_{4}\right](\mathrm{OH})_{2}\right)$. It is evident that platinum metal particles are dispersed uniformly in the carbon particles and the average diameter of the platinum particles is about $22 \mathrm{~nm}$. In addition, the surface morphology of the carbon particles containing platinum metal was not affected by HTT.

The results obtained in the system using $\mathrm{Cu}(\mathrm{OH})_{2}$ are given in Figures 3 and 4 . The $\mathrm{X}$-ray diffraction patterns(Figure 3) show that above HTT of $500^{\circ} \mathrm{C}$ new peaks appear, which are assigned to copper metal, and their intensities increase with HTT. Figure 4(a) demonstrates that the surface of the carbon- $\mathrm{Cu}(\mathrm{OH})_{2}$ particles as prepared is very smooth, but for the samples treated at $700^{\circ} \mathrm{C}$ or above, small particles stick on the carbon

(a)
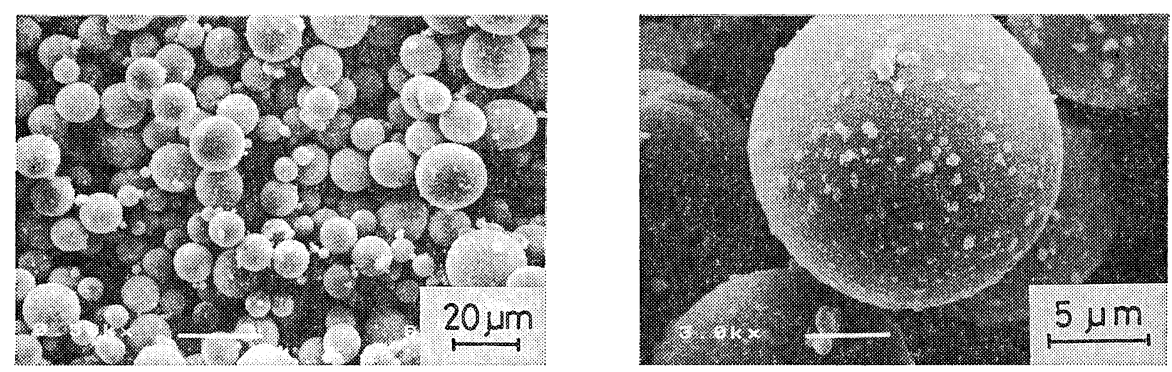

a s p r e p.
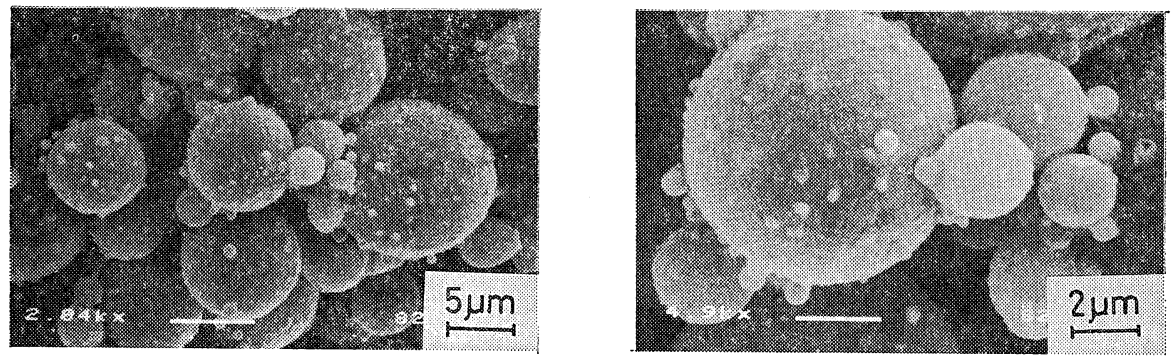

HTT $1000^{\circ}$

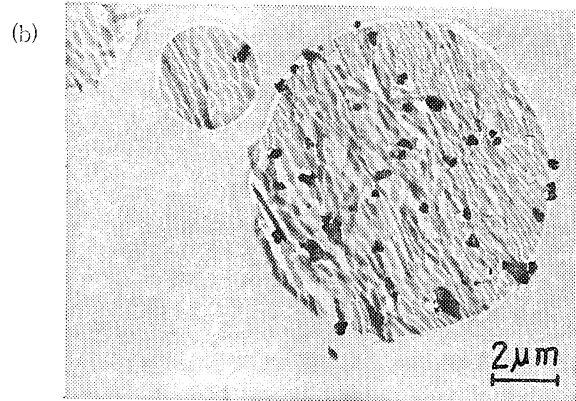

Fig. 5 (a) Electron micrographs of spherical carbon particles containing 10 wt $\% \mathrm{AgNO}_{3}$ with $\mathrm{HTT}$; (b) sectional view of the sample heat-treated at $1000^{\circ} \mathrm{C}$. 
particles. These small particles were confirmed to be copper metal by EPMA. This result can be interpreted as follows. As HTT increases, $\mathrm{Cu}(\mathrm{OH})_{2}$ in the carbon matrix decompose to copper metal. A further increment of HTT causes the copper metal to diffuse to the external surface due to a poor compatibility between copper metal and carbon, resulting in formation of copper particles on the surface of the carbon particles. In this case, copper metal particles were hardly observed in the bulk carbon particles heat-treated at $1000^{\circ} \mathrm{C}$ from the sectional view (Figure 4 (b)).

In the system using $\mathrm{AgNO}_{3}$, spherical particles were also obtained, but even in as-prepared samples, fine irregular particles, which are assigned to silver metal, covered on the carbon particles (Figure 5(a)). There is a possibility that $\mathrm{AgNO}_{3}$ is reduced to silver metal with hydrophilic groups of amphiphilic carbonaceous material. Since $\mathrm{AgNO}_{3}$ is easily reduced to silver metal, X-ray diffraction peaks corresponding to silver metal are observed for even as-prepared sample (Figure 6). The cross section of the carbon beads (Figure $5(\mathrm{~b})$ )

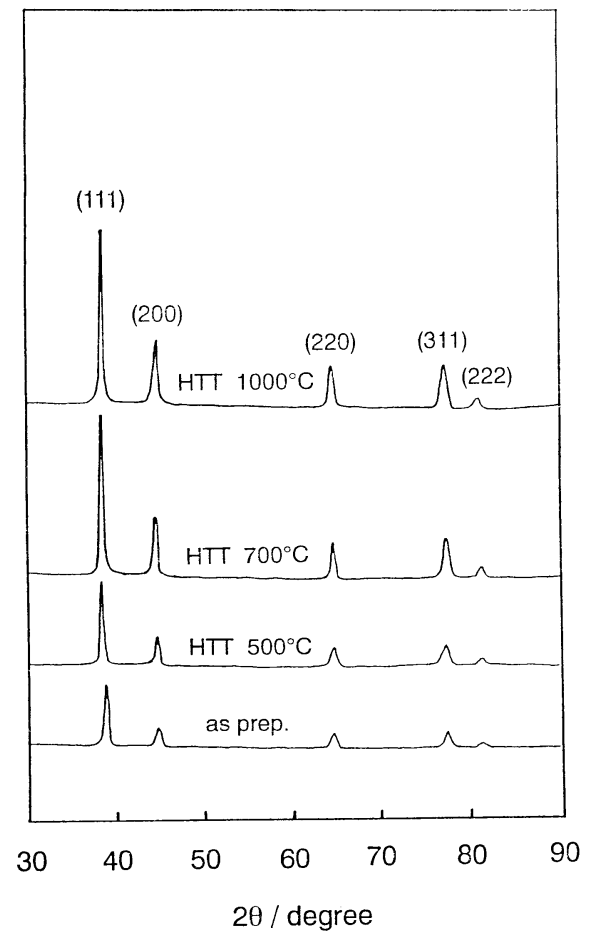

Fig. 6 Change in X-ray diffraction pattern of carbon spherical particles containing $10 \mathrm{wt} \% \mathrm{AgNO}_{3}$ with HTT. shows that tiny silver particles also exist in the matrix of the carbon, although carbon material in the matrix is, to some extent, destroyed in the preparation of cross sectional sample.

Thus, it is concluded that spherical carbon-metal salt composites are obtained by the emulsion method using homogeneous alkaline solutions containing amphiphilic carbonaceous material and a metal salt. The subsequent heattreatment provides spherical carbon-metal particles whose morphology is dependent on the kind of metal salt.

The formation of spherical carbon-metal particles using ammonia water solutions containing both amphiphilic carbonaceous material and a metal salt may open new possibilities in the preparation of heterogeneous catalysts.

\section{References}

1) M.Fujii, Y.Yamada, T.Imamura, and H.Honda : 18 th Biennial Conference on Carbon, p.405, 1987.

2) JPN Patent, 64-9288, 1989.

3) D.Tateishi, K.Esumi, and H.Honda: Carbon, 29, 1296 (1991).

4) R.Warren, C.H.Anderson, and M.Carlsson: J. Mater. Sci., 13, 178 (1978).

5) M.S.Dresselhaus and G.Dresselhaus: Adv. Phys., 30, 139 (1981)

6) R.Ehrburger, A.Mongilardi, and J.Lahaye: J. Colloid Interface Sci., 91 , 151(1983).

7) S.Miyanaga, H.Yasuda, A.Hiwara, A.Nakamura, and H.Sakai : J. Macromol. Sci.-Chem., A 27, 1347 (1990).

8) K.Esumi, H.Sugii, D.Tateishi, and H.Honda : Carbon, 30, $944(1992)$. 